\title{
A psicologia na saúde: entre a clínica e a política
}

\author{
Laura Belluzzo de Campos Silva
}

\section{RESUMO}

Este trabalho visa discutir o lugar da psicologia na saúde na sociedade contemporânea. Partindo das proposições de Canguilhem, para quem a saúde é um valor inerente à vida, definido por uma normatividade biológica, problematiza a relevância da clínica e do sujeito na definição do que é saúde e doença. Por fim, considerando a afirmação do autor de que a saúde é um bem coletivo, estabelece um diálogo deste com Foucault, que demonstra que o cuidado com a saúde da população, a partir de determinado momento histórico, passa a ser uma forma de normalização e de exercício do poder disciplinar.

Palavras-chave: Psicologia. Saúde. Psicologia da saúde. Foucault. Canguilhem.

\section{Psychology and health: between the clinic and politics}

\begin{abstract}
This work aims at an examination of the place of psychology in relation to health practices in contemporary society. Following Canguilhem, for whom health is an inherent value to life and defined as biological normativeness, it questions the relevance of the clinic and of subject in the definition of health and illness. On the other hand, considering Canguilhem's notion of health as a collective good, it establishes a dialogue with Foucault, to demonstrate that health care, at a determined historical moment, becomes a form of normalization and exercise of disciplinary power.
\end{abstract}

Keywords: Psychology. Health. Health psychology. Foucault. Canguilhem.

* Psicóloga, Mestre e Doutora em Psicologia Social pelo Instituto de Psicologia da USP; Docente e Pesquisadora do Programa de Pós-Graduação em Psicologia da Saúde da Universidade Metodista de São Paulo. Autora de Doença mental, psicose, loucura: representações e práticas da equipe multiprofissional de um Hospital-Dia (São Paulo, Casa do Psicólogo, 2001) e co-autora de Psicologia da saúde: temas de reflexão e prática, (UMESP, 2003), entre outros. E-mail: laurabelluzzo@bol.com.br 


\section{INTRODUÇÃO}

O campo de atuação do psicólogo vem-se expandindo para além das fronteiras tradicionais do cuidado à saúde mental, de modo que esse profissional vem sendo cada vez mais requisitado para o exercício de uma série de intervenções preventivas e/ou terapêuticas voltadas para o cuidado da saúde somática.

Prova disso é a criação de uma nova área de estudos e intervenções - a "Psicologia da Saúde" - que ressalta a importância dos comportamentos de prevenção e cuidados com a saúde o que, por sua vez, parece ser corroborado pelo forte apelo dos meios de comunicação de massa ao homem comum, haja vista a prevalência de artigos sobre o tema veiculados pela mídia impressa e televisiva.

No entanto, em que pese a contribuição que a psicologia tem trazido para esse campo, há algumas questões na relação entre psicologia e saúde que merecem ser mais bem debatidas. Uma pesquisa realizada recentemente com pesquisadores e psicólogos do Brasil, Espanha e Argentina revelou "uma certa dificuldade, por parte dos participantes, de pontuarem com clareza o conceito de saúde utilizado desde sua perspectiva teórica" (SARRIERA, et al., 2003, p. 97) o que, segundo os autores, indica uma falta de problematização de conceitos básicos da área da psicologia.

Visando trazer algumas reflexões teóricas que possam contribuir para pensar o lugar ocupado pela psicologia e, conseqüentemente, pelos psicólogos, no contexto da saúde na contemporaneidade, propomos algumas articulações entre o conceito de saúde de Canguilhem e o pensamento de Foucault.

\section{EM BUSCA DO CONCEITO DE SAÚDE}

Não é difícil concordar com Dejours (1986, p. 8), quando afirma que a definição proposta pela Organização Mundial de Saúde é vaga e idealizada

A definição internacional diz que a saúde seria esse estado de conforto, de bem-estar físico, mental e social... gostaríamos de tecer uma crítica a essa definição. Em nosso entender, há duas razões para esta crítica: a primeira é que esse estado de bem-estar e de conforto, se nos aprofundarmos um pouco mais, é impossível de definir. Gostaríamos que nos dessem uma definição desse perfeito estado de bem-estar. Não sabemos o que é e cremos que não haja esclarecimentos consideráveis sobre a questão. É muito vaga. Implícita e intuitivamente sabese que isso significa alguma coisa, mas quando se trata de defini-la, não é muito simples. E a segunda crítica a fazer é que, no fundo, esse perfeito e completo estado de bem-estar não existe!

Posto isso, já que pretendemos problematizar o conceito de saúde, e mais especificamente, o de saúde somática, partimos de Canguilhem. 


\section{O CONCEITO DE SAÚDE SOMÁTICA}

Em $O$ normal e o patológico, Canguilhem opta por se ater apenas ao estudo das doenças somáticas e inicia desmontando o dogma, bastante difundido no século XIX, de que haveria uma identidade real dos fenômenos vitais normais e patológicos e que as diferenças entre um estado e outro seriam apenas quantitativas. Dogma esse que, por sinal, influenciou significativamente a psicologia.

A evolução da anatomia patológica levou à fisiologia, de modo que a classificação nosográfica encontrou um substrato na decomposição anatômica.

Essa evolução resultou na formação de uma teoria das relações entre o normal e o patológico, segundo a qual os fenômenos patológicos nos organismos vivos nada mais são do que variações quantitativas, para mais ou para menos, dos fenômenos fisiológicos correspondentes (CANGUILHEM, 1990, p. 22).

$\mathrm{Na}$ França, esse dogma foi exposto, segundo condições e objetivos bem diferentes, por Augusto Comte e Claude Bernard. Na doutrina de Comte, baseada no princípio de Broussais, ${ }^{1}$ o interesse se dirige do patológico para o normal, com a finalidade de determinar especulativamente as leis do normal, e a doença é considerada digna de estudos sistemáticos na medida em que substitui uma experimentação biológica muitas vezes impraticável, principalmente no homem. Para Claude Bernard, cujas conclusões foram baseadas em uma vida inteira dedicada à experimentação biológica, o interesse se dirige do normal para o patológico, com a finalidade de uma ação racional sobre as doenças. Em Comte, a afirmação da identidade permanece puramente concepitual, enquanto Claude Bernard tenta precisar essa identidade numa interpretação de caráter quantitativo e numérico (CANGUILHEM, 1990, p. 23).

Se o que motiva o pai da medicina experimental é a cura das doenças, a ambição que anima o criador da doutrina positivista é a tentativa de, além de codificar os métodos científicos, elevar sua concepção nosológica à categoria de axioma geral, o que poderia até mesmo ser estendido ao âmbito social:

$\mathrm{O}$ regime enciclopédico o estenderá sobretudo às funções intelectuais e morais, às quais o princípio de Broussais ainda não foi condignamente aplicado[...] além de sua eficácia direta para as questões biológicas, ele constituirá, no sistema geral da educação positiva, uma vantajosa preparação lógica aos processos análogos para com a ciência final. Pois o organismo coletivo, em virtude de sua complexidade superior, comporta perturbações ainda mais graves, mais variadas e mais frequientes que as do organismo individual. Não tenho medo de assegurar que o princípio de Broussais deve ser estendido até esse ponto, e já o apliquei nesse campo para confirmar ou aperfeiçoar as leis sociológica (CANGUILHEM, 1990, p. 29). 
A intenção de Comte, ao estabelecer essa analogia e propor a ampliação do alcance do princípio de Broussais, era defender sua doutrina política e provar que a terapêutica das crises políticas consistiria em trazer as sociedades de volta à sua estrutura essencial e permanente e em só tolerar o progresso nos limites de variação da ordem natural definitiva pela estática social (CANGUILHEM, 1990, p. 42).

Contra a formulação de Comte, Canguilhem observa que ele não oferece exemplos da medicina e que, ao tentar definir o que é normal, refere-se ao conceito de harmonia, que é um conceito qualitativo, estético e moral. Além disso, ao definir o patológico como mais ou menos que o normal, não precisa as noções de excesso e de falta, atribuindo ao normal um valor, de modo que o normal passa a ser normativo, fazendo com que um ideal de perfeição paire sobre essa tentativa de definição positiva (CANGUILHEM, 1990, p. 35, 36).

Em suma, para Canguilhem (1990, p. 36), a tentativa de tornar a patologia e, consequientemente, a terapêutica, integralmente científicas só teria sentido se fosse possível dar-se uma definição puramente objetiva do normal como um fato, e, além disso, traduzir qualquer diferença entre o estado normal e o patológico em termos de quantidade, exigências que nem a doutrina de Comte nem a de Broussais cumpriram.

A perspectiva formulada por Claude Bernard, por sua vez, já que parte do pressuposto de que uma terapêutica eficaz supõe uma patologia experimental, que não se separa de uma fisiologia, traz para sustentar seu princípio geral de patologia, ao contrário de Broussais e Comte, argumentos controláveis, protocolos de experiências e, sobretudo, métodos de quantificação dos conceitos fisiológicos. Mas ainda assim há ambigüidade em seu pensamento, pois confunde quantitativo com qualitativo, ambigüidade que é instrutiva, pois leva a pensar se o conceito de doença é o conceito de uma realidade objetiva acessível ao conhecimento científico quantitativo (CANGUILHEM, 1990, p. 52, 53).

Portanto, a saúde perfeita não existe a não ser como um conceito normativo de um tipo ideal. Dizer que a saúde perfeita não existe é apenas dizer que o conceito de saúde não é o de uma existência, mas sim o de uma norma cuja função e cujo valor é relacionar esta norma com a existência, a fim de provocar a modificação desta. O que não significa que o conceito de saúde seja um conceito vazio (CANGUILHEM, 1990, p.54).

Canguilhem demonstra que entre o estado normal e o patológico há diferenças qualitativas que não podem ser traduzidas apenas em diferenças quantitativas, defendendo a tese de que o estado patológico não é um simples prolongamento quantitativamente variado do estado fisiológico, é totalmente diferente. A necessidade de restabelecer a continuidade entre a saúde e a doença é tal que, no limite, a noção de doença se esvaneceria. É a partir do patológico que se decifra o ensinamento da saúde. Com o advento da fisiologia, a doença deixou de ser objeto de angústia para o homem são e tornou-se objeto de estudo para o teórico da saúde. 
No entanto, afirma o autor, a análise fisiológica de funções separadas só sabe que está diante de fatos patológicos devido a uma informação clínica prévia (CANGUILHEM, 1990, p. 65) e o fato patológico só pode ser apreendido como tal, isto é, como alteração do estado normal, ao nível da totalidade orgânica e, em se tratando do homem, ao nível da totalidade individual consciente, em que a doença se torna uma espécie de mal (CANGUILHEM, 1990, p. 64).

Abre-se, então, um descompasso entre o plano da fisiologia e o plano do homem concreto, havendo o risco de a fisiologia fazer uma mistura ilegítima do cálculo abstrato das identidades e a apreciação concreta das diferenças, daí a importância da clínica.

Ser doente é, realmente, para o homem, viver uma vida diferente, mesmo no sentido biológico da palavra. A doença é uma forma diferente de vida.

É de um modo bastante artificial, parece, que dispersamos a
doença em sintomas ou a abstraímos de suas complicações.
O que é um sintoma, sem contexto, sem pano de fundo? O
que é uma complicação, separada daquilo que a complica?
Quando classificamos como patológico um sintoma ou um
mecanismo funcional isolado, esquecemos que aquilo que os
torna patológicos é sua relação de inserção na totalidade
indivisível de um comportamento individual. De tal modo
que a análise fisiológica de funções separadas só sabe que
está diante de fatos patológicos devido a uma informação
clínica prévia; pois a clínica coloca o médico em contato com
indivíduos completos e concretos e não com seus órgãos ou
suas funções. A patologia, quer seja anatômica ou fisiológica,
analisa para melhor conhecer, mas ela só pode saber que é
uma patologia - isto é, estudo dos mecanismos da doença -
porque recebe da clínica essa noção de doença cuja origem
deve ser buscada na experiência que os homens têm de suas
relações de conjunto com o meio (CANGUILHEM, 1990, p.
64-65).

O descompasso entre a doença sentida pelo doente e a doença tal como entendida pelo médico ficará mais evidente na concepção de Leriche, que leva em conta a opinião do doente, definindo saúde como "a vida no silêncio dos órgãos" e doença como aquilo que perturba os homens no exercício normal de sua vida e em suas ocupações e, sobretudo, como aquilo que os faz sofrer (CANGUILHEM, 1990, p. 67).

Ao definir a doença por seus efeitos, Leriche abriu caminho para deixarmos o plano da ciência abstrata pela esfera da consciência concreta. A doença seria então um fato que ocorre ao nível do todo individual consciente, e é um fato que as finas análises de Leriche [...] nos permitem qualificar como comportamentos (CANGUILHEM, 1990, p. 73).

A diferença entre a concepção de Leriche e a de seus antecessores é que o primeiro partiu da técnica clínica e cirúrgica suscitadas pelo estado patológico, ao 
passo que Comte defendia a independência da biologia teórica em relação à medicina e à terapêutica, enquanto Claude Bernard, embora partisse inicialmente da clínica, não atribuía ao fato patológico a mesma dignidade teórica que a explicação fisiológica (CANGUILHEM, 1990, p.79).

Para Leriche, ao contrário, a fisiologia é a coletânea das soluções dos problemas levantados pelas doenças dos doentes. O campo de possíveis da fisiologia só seria revelado pela doença. As doenças seriam virtualidades da fisiologia, que só poderiam ser conhecidas a partir da experiência da doença. A doença, e não a saúde, portanto, seria o ponto de partida da Medicina e de um interesse do ser vivo (no caso, o homem) pelo estudo da própria vida. "A doença está na origem da atenção especulativa que a vida dedica à vida".

Para Canguilhem, mesmo nos casos atuais em que as doenças podem ser detectadas antes de qualquer sintoma apresentado pelo doente, o diagnóstico só foi possível a partir da manifestação dos sintomas apresentada na clínica. Quem determina o valor da doença é o doente - é a vida em si mesma e não a apreciação médica que faz do normal biológico um conceito de valor.

Segundo Jaspers (apud CANGUILHEM, 1990, p. 93), "É o médico quem menos procura o sentido das palavras doença e saúde". Do ponto de vista da ciência, ele trata dos fenômenos vitais, mas a definição do que é doença parte menos dos médicos que da apreciação dos doentes e das idéias dominantes do meio social.

O fato patológico só pode ser compreendido como tal ao nível da totalidade orgânica e da experiência que os homens têm de suas relações de conjunto com o meio. Para Canguilhem, o conceito de normal que a medicina e a fisiologia estariam usando, sem ter clareza disso, seria, portanto, um julgamento de valor e não um julgamento de realidade.

\section{Clínica, SAúde e SuJeito}

A perspectiva desenhada por Canguilhem abre então uma distância entre a doença, tal como é vivida pelo doente, e sua explicação fisiológica. Mas que espaço é esse que a clínica inaugura? Trata-se do espaço do sujeito.

Embora Canguilhem não tenha usado esse termo, a leitura de Foucault nos autoriza a fazer essa suposição, pois, para Foucault, o nascimento da clínica é indicativo do aparecimento de uma nova experiência da doença que se caracteriza pelo desaparecimento das entidades mórbidas em proveito da articulação da doença com o organismo e do surgimento da própria possibilidade de um discurso sobre a doença (FOUCAULT, 2003, p. 13, 14).

Segundo Foucault (2003, p. 8, 9), o surgimento da experiência clínica advém de uma mutação no discurso médico que fez com que os poderes de um espaço visionário por meio do qual se comunicavam médicos e doentes, fisiólogos e práticos (nervos tensos e retorcidos, órgãos endurecidos ou queimados etc.) fossem deslocados e como que encerrados na singularidade do doente, na região dos sintomas subjetivos, de modo que: 
O olhar não é mais redutor, mas fundador do indivíduo em sua qualidade irredutível [...] o objeto do discurso também pode ser um sujeito, sem que as figuras da objetividade sejam por isso alteradas. Foi esta reorganização formal em profundidade, mais do que o abandono das teorias e dos velhos sistemas, que criou a possibilidade de uma experiência clínica: ela levantou a velha proibição aristotélica; poder-se-á, finalmente, pronunciar sobre o indivíduo um discurso de estrutura científica (FOUCAULT, 2003, p. 13).

Se retomarmos a máxima canguilhemiana de que

o fato patológico só pode ser compreendido como tal ao nível da totalidade orgânica e da experiência que os homens têm de suas relações de conjunto com o meio", poderíamos concluir que a definição última do que é doença ou saúde estaria diretamente relacionada à verdade de cada sujeito, ou, no máximo, à verdade de grupos de sujeitos submetidos às condições do mesmo meio. Mas se assim fosse, ou cairíamos num relativismo estéril ou correríamos o risco de deixar apenas para a sociedade determinar o que é doença ou não. É então na vida que o autor vai buscar a origem da normatividade inerente ao vivente humano e, a partir desta, o ideal de saúde a ser atingido: "O vivente humano prolonga, de modo mais ou menos lúcido, um efeito espontâneo, próprio da vida, para lutar contra aquilo que constitui um obstáculo a sua manutenção e a seu desenvolvimento tomados como normas (CANGUILHEM, 1990, p. 98).

Assim a vida é considerada uma atividade normativa, já que institui normas (CANGUILHEM, 1990, p. 97). As ciências da vida são as únicas que têm patologia, não é possível, por exemplo, falar em patologia na mecânica, porque a vida está longe de ser indiferente às condições que lhe são impostas, a vida é polaridade (CANGUILHEM, 1990, p. 99). A técnica humana prolonga impulsos vitais a serviço dos quais tenta colocar um conhecimento sistemático que os livraria das tentativas e erros da vida, que são inúmeros, e muitas vezes saem caro. Portanto, é o vivente humano que diz à Medicina o que é normal e, portanto, qual é o ideal de saúde a ser atingido.

O papel da fisiologia seria, então, o de detectar o conteúdo das normas dentro das quais a vida conseguiu se estabilizar, a fisiologia é a ciência das condições da saúde ou ciência dos ritmos estabilizados da vida. A saúde seria a indeterminação inicial da capacidade de instituição de novas normas biológicas. Ser sadio significa não apenas ser normal em uma situação determinada, mas ser normativo - a saúde é uma margem de tolerância em relação às infidelidades do meio.

Há, portanto, uma normatividade biológica, inerente à vida.

Mas cabe a nós questionar: se a normatividade foi deslocada para o plano da vida, qual o lugar do sujeito nesse contexto? Qual a relação entre vida e sujeito? 
Talvez o que possamos considerar como indício de resposta para essa questão sejam as teorias do stress e psicossomática - mencionadas por Canguilhem nos ensaios que 20 anos depois deram origem à versão revisada de sua obra - a partir das quais vai-se começar a estabelecer uma relação entre o adoecimento somático e o meio não apenas físico, mas social, mediada pelo psiquismo. Essas teorias permitem supor que houve uma expansão do espaço ocupado pelo sujeito no adoecimento somático, uma vez que este, a partir de agora, além de ser o que aponta o sofrimento de seu corpo na clínica, passa a ser também o responsável por vários tipos de doenças que o acometem, de modo que a psicologia passa também a estar implicada com a definição do que é doença e saúde.

É o que Foucault nos esclarece, acrescentando que a psicologia, ao se constituir como ciência, já teria herdado da biologia a divisão entre normal e patológico. Para Foucault (2003, p. 13), aliás, a própria clínica não teria condições de legislar sozinha sobre o normal e o patológico se não houvesse um fundo de saber instituído sobre o qual o "colóquio singular" com o cliente pudesse ser rebatido:

O prestígio das ciências da vida, no século XIX, o papel do modelo que desempenharam, sobretudo nas ciências do homem, está ligado originariamente, não ao caráter compreensivo e transferível dos conceitos biológicos, mas ao fato de que estes conceitos estavam dispostos em um espaço cuja estrutura profunda respondia à oposição entre sadio e mórbido. Quando se falar da vida dos grupos e das sociedades, da vida da raça, ou mesmo da "vida psicológica" não se pensará apenas na estrutura interna do ser organizado, mas na bipolaridade médica do normal e do patológico. A consciência vive, na medida em que pode ser alterada, amputada, afastada de seu curso, paralisada; as sociedades vivem, na medida em que existem algumas, doentes, que se estiolam, e outras, sadias, em plena expansão; a raça é um ser vivo que degenera; como também as civilizações, de que tantas vezes se pôde constatar a morte. Se as ciências do homem apareceram no prolongamento das ciências da vida, é talvez porque estavam biologicamente fundadas, mas é também porque o estavam medicamente; sem dúvida por transferência, importação e, muitas vezes, metáfora, as ciências do homem utilizaram conceitos formados pelos biólogos; mas o objeto que eles se davam (o homem, suas condutas, suas realizações individuais e sociais) constituía, portanto, um campo dividido segundo o princípio do normal e do patológico. Daí o caráter singular das ciências do homem, impossíveis de separar da negatividade em que apareceram, mas também ligadas à positividade que situam, implicitamente, como norma (FOUCAULT, 2003, p. 40).

É interessante destacar ainda que nessa revisão, Canguilhem aponta o advento da noção de patologia como erro metabólico e o risco de se empreender uma caça aos genes heterodoxos com uma inquisição genética, o que leva o autor a 
questionar quem definiria o que é erro e, ainda: como considerar erro algo que foi produzido pela vida. Erro para quem? Para o homem? Para a vida? (CANGUILHEM, 1990, p. 255).

Essas indagações, que poderiam nos levar a pensar que estaria havendo uma mudança no conceito de saúde em função das novas descobertas no campo da biologia e da medicina, não fazem com que Canguilhem abandone sua posição, mas permitem supor que estaria havendo um novo deslocamento do lugar do sujeito em que seu poder de indicar seu sofrimento diminui, uma vez que este poderá ser previsto a partir do mapeamento de seus genes, enquanto sua responsabilidade por seu adoecimento aumenta, quando cada vez mais é levado a crer que as doenças que adquire dependem em grande parte de sua subjetividade.

\section{ENTRE A NORMATIVIDADE BIOLÓGICA E A NORMATIVIDADE SOCIAL}

Encerrando nosso percurso pela obra de Canguilhem, podemos concluir que o autor, embora reconheça o peso das normas sociais nas questões ligadas à saúde, não reduz o biológico ao social, defendendo a anterioridade das exigências da vida em relação às da sociedade.

Para ele, "a definição de normas higiênicas supõe o interesse que se dá - do ponto de vista político - à saúde das populações considerada estatisticamente, à salubridade das condições de vida, à extensão uniforme dos tratamentos preventivos e curativos elaborados pela medicina" (CANGUILHEM, 1990, p. 218).

Segundo Canguilhem, normal é o termo pelo qual o século XIX iria designar o protótipo escolar e o estado de saúde orgânica. Tanto a reforma hospitalar, como a reforma pedagógica exprimem uma exigência de racionalização que se manifesta também na política, como se manifesta na economia, sob a influência de um maquinismo industrial nascente que levará enfim ao que se chamou desde então de normalização. Para o autor, a normalização tanto dos meios técnicos da educação quanto da saúde (e outros) é expressão de exigências coletivas cujo conjunto define, em determinada estrutura, aquilo que considera seu bem particular, mesmo que não haja uma tomada de consciência por parte dos indivíduos (CANGUILHEM, 1990, p. 209-210).

Mas, não obstante esse interesse político, para o autor, é a anterioridade histórica do futuro anormal que provoca uma intenção normativa. Assim sendo, "é a doença ou o mal-estar" que antecede a necessidade de normalizar ou normatizar. Para ele, portanto, é a saúde, como um valor inerente à vida, que justificaria a necessidade de normalizar a sociedade (CANGUILHEM, 1990, p. 216).

\section{SAÚdE E PODER}

De uma perspectiva oposta, Foucault vai demonstrar como esses saberes, inicialmente a medicina e, depois, as ciências humanas, passam a ter um lugar significativo na expressão do poder. "A disciplina é o conjunto de técnicas pelas quais os sistemas de poder vão ter por alvo e resultado os indivíduos em sua singularidade" (FOUCAULT, 1979, p. 107). 
Para Foucault (1979, p. 79), o cuidado com a saúde da coletividade, a partir de determinado momento na história, passa a ser exercido como uma forma de poder, a partir do qual os governos visam preservar a força militar e a força de trabalho de suas populações.

Segundo Foucault, a medicina moderna, científica, que nasceu em fins do século XVIII, é uma medicina social que tem por background uma certa tecnologia do corpo social. A hipótese defendida por Foucault $(1979$, p. 80) é a de que

Com o capitalismo não se deu a passagem de uma medicina coletiva para uma medicina privada, mas justamente o contrário; [...] o capitalismo, desenvolvendo-se em fins do século XVIII e início do século XIX, socializou um primeiro objeto que foi o corpo enquanto força de produção, força de trabalho. O controle da sociedade sobre os indivíduos não se opera simplesmente pela consciência ou pela ideologia, mas começa no corpo... com o corpo. Foi no biológico, no somático, no corporal que, antes de tudo, investiu a sociedade capitalista. $\mathrm{O}$ corpo é uma realidade bio-política. A medicina é uma estratégia bio-política.

Foucault esclarece que, apesar de o corpo ter sido investido política e socialmente como força de trabalho, o que parece característico da evolução da medicina social, ou seja, da própria medicina, no Ocidente, é que não foi a princípio como força de produção que o corpo foi atingido pelo poder médico. Foi somente em último lugar que se colocou o problema do corpo, da saúde e do nível da força reprodutiva dos indivíduos. Antes da medicina que ele denominou de medicina da força de trabalho, houve duas etapas: a da medicina de estado e a da medicina urbana (FOUCAULT, 1979, p. 80).

Desde o final do século XVI e começo do século XVII, período dominado pelo mercantilismo, todas as nações do mundo europeu se preocuparam com o estado de saúde de sua população. Sendo o mercantilismo não apenas uma teoria econômica, mas, também, uma prática política que consiste em controlar os fluxos monetários entre as nações, os fluxos de mercadorias correlatos e a atividade produtora da população, a política mercantilista consiste essencialmente em majorar a produção da população, a quantidade de população ativa, a produção de cada indivíduo ativo e, a partir daí, estabelecer fluxos comerciais que possibilitem a entrada, no Estado, da maior quantidade possível de moeda, graças ao que se poderá pagar os exércitos e tudo o que assegure a força real de um Estado com relação aos outros.

Nessa perspectiva, a França, a Inglaterra e a Áustria começaram a calcular a força ativa de suas populações, elaborando estatísticas de nascimento e mortalidade, com a preocupação de aumentar a população, sem, no entanto, nenhuma intervenção efetiva ou organizada para elevar o nível da saúde (FOUCAULT, 1979, p. 82).

Já na Alemanha, país em que se instituiu o primeiro Estado moderno, vaise desenvolver uma prática médica centrada na melhoria do nível de saúde da 
população, baseada em um sistema completo de observação da morbidade, na normalização da prática e do saber médico, em uma organização administrativa para controlar a atividade dos médicos e na criação de funcionários médicos nomeados pelo governo, com responsabilidade sobre uma determinada região (FOUCAULT, 1979, p. 83,84).

Essa medicina de Estado que aparece de maneira bastante precoce, antes mesmo da formação da grande medicina científica de Morgani e Bichat, não tem por objeto a formação de uma força de trabalho adaptada às necessidades das indústrias que se desenvolviam neste momento. Não é o corpo que trabalha, o corpo do proletário que é assumido por essa administração estatal da saúde, mas o próprio corpo dos indivíduos enquanto constituem globalmente o Estado: é a força, não do trabalho, mas estatal, a força do Estado em seus conflitos, econômicos, certamente, mas igualmente políticos, com seus vizinhos. É essa força estatal que a medicina deve aperfeiçoar e desenvolver. Há uma espécie de solidariedade econômico-política nesta preocupação da medicina de Estado (FOUCAULT, 1979, p. 84).

A segunda direção no desenvolvimento da medicina social é representada pelo exemplo da França, na qual, em fins do século XVIII aparece uma medicina social que tem como suporte um fenômeno inteiramente diferente: a urbanização (FOUCAULT, 1979, p. 85).

As tensões políticas e econômicas decorrentes da urbanização geram a necessidade de um poder político capaz de esquadrinhar esta população urbana para lidar com os afrontamentos entre ricos e pobres, com as revoltas, saques, roubos, e, ainda, com o medo gerado pelo amontoamento da população e pelas epidemias urbanas.

A classe burguesa lança mão do modelo de intervenção da quarentena, que já havia sido aplicado na Idade Média como um regulamento de urgência em todos os países da Europa, quando a peste ou uma doença epidêmica violenta aparecia em uma cidade.

O esquema da quarentena suscitado pela peste constituiu-se, juntamente com o modelo de exclusão suscitado pela lepra, como um dos dois grandes modelos de organização médica da civilização ocidental. $\mathrm{O}$ da lepra, funcionando a partir da purificação do espaço urbano com a exclusão do leproso, e o da peste, consistindo em distribuir os indivíduos uns ao lado dos outros, isolando-os de modo a poder vigiar o estado de saúde de cada um, promovendo um esquadrinhamento do espaço social que permite que este seja percorrido por um olhar permanente e controlado por um registro. Se o que anima o modelo da lepra é o modelo religioso da purificação, a inspiração da quarentena é a revista militar (FOUCAULT, 1979, p. 88).

É com a medicina urbana que aparece a noção de salubridade e que a medicina passa da análise do meio à dos efeitos do meio sobre o organismo. 
O terceiro tipo de medicina social a que Foucault se refere surge na Inglaterra, país em que o desenvolvimento industrial e, por conseguinte, o desenvolvimento do proletariado foi o mais rápido e o mais importante. Essa nova forma de medicina social tem como objetivos ajudar os mais pobres a satisfazer suas necessidades de saúde, uma vez que sua pobreza não lhes permite que o façam por si mesmos, e, ao mesmo tempo, exercer um controle da saúde e do corpo das classes mais pobres para torná-las mais aptas ao trabalho e menos perigosas às classes ricas, garantindo que estas não sejam vítimas de fenômenos epidêmicos originários da classe pobre (FOUCAULT, 1979, p. 95).

\section{ENTRE A NORMATIVIDADE SOCIAL E A NORMATIVIDADE BIOLÓGICA}

Qual a relação que se pode estabelecer então entre o pensamento de Canguilhem e o de Foucault? Será necessário optar entre o conceito de saúde como expressão de uma normatividade biológica inerente à polaridade da vida ou ver a definição de saúde como efeito de normas sociais? A saída não é tão simples.

Cremos que Deleuze nos esclarece ao afirmar que entre as formações nãodiscursivas de instituições e as formações discursivas de enunciados não se estabelece nem uma espécie de paralelismo vertical (em que uma simboliza a outra relações primárias de expressão), nem uma causalidade horizontal, segundo a qual os acontecimentos ou instituições determinariam os homens enquanto supostos autores de enunciados (relações secundárias de reflexão). Para ele, impõe-se um terceiro caminho - diagonal - de relações discursivas com os meios não-discursivos, que não são em si mesmos internos nem externos ao grupo de enunciados, mas que constituem o limite, o horizonte determinado sem o qual tais objetos de enunciados não poderiam aparecer, nem tal lugar ser reservado dentro do próprio enunciado (DELEUZE, 1991, p. 21). E citando Foucault (apud DELEUZE, 1991):

Não, claro, que seja a prática política que desde o começo do século XIX teria imposto à medicina novos objetos, como as lesões dos tecidos orgânicos ou as correlações anátomopatológicas; mas ela abriu novos campos de demarcação dos objetos médicos... massa da população administrativamente enquadrada e fiscalizada... grandes exércitos populares... instituições de assistência hospitalar em função das necessidades econômicas da época e da posição recíproca das classes sociais. Essa relação da prática política com o discurso médico também vemos nascer no estatuto dado ao médico.

\section{Como PENSAR O LUGAR DA PSICOlogia NA SAÚde?}

Os encaminhamentos formulados nesse texto permitem apenas fazer algumas suposições que deverão ser desenvolvidas posteriormente. Será possível ainda pensar a saúde como decorrente de uma normatividade biológica no momento em que a decifração do genoma humano foi concluída? Será que a definição do que é doença ainda depende do sujeito que sofre, ou foi deslocada como sendo o 
efeito virtual de "erros" genéticos? Até que ponto o homem, ao adquirir a possibilidade de alterar sua constituição genética, interfere na normatividade biológica?

E em relação ao lugar que a saúde ocupa na sociedade? Hoje, não mais a sociedade disciplinar e sim a sociedade de controle "na qual os mecanismos de comando se tornam cada vez mais "democráticos", cada vez mais imanentes ao campo social, distribuídos por corpos e cérebros dos cidadãos"e em que o poder é "exercido mediante máquinas que organizam diretamente o cérebro (sistemas de comunicação, redes de informação) e os corpos (sistemas de bem-estar, atividades monitoradas etc.) no objetivo de um estado de alienação independente do sentido da vida e do desejo de criatividade (HARDT; NEGRI, 2002, p. 42). A passagem da sociedade disciplinar para a sociedade de controle não significa, de forma alguma, o fim da disciplina, e sim seu exercício imanente, isto é, a autodisciplina dos sujeitos, de tal modo que hoje esta se exerce dentro das próprias subjetividades.

Talvez possamos pensar, à guisa de conclusão parcial, que o lugar do sujeito na clínica vem sendo deslocado, deixando de ser aquele que aponta seu sofrimento, na medida em que este é agora anunciado pelas novas tecnologias, antes mesmo que qualquer indício de sofrimento apareça em seu corpo. Por outro lado, paradoxalmente, com o advento da sociedade de controle, estaríamos assistindo a um aumento da responsabilidade atribuída ao sujeito tanto por seu adoecimento como pela prevenção deste.

Essas duas perspectivas nos levam a pensar que o lugar da psicologia na saúde situa-se entre dois pólos: o de resgatar para o sujeito o lugar na clínica que este perdeu - o de dizer do que sofre - de onde sai a vertente da humanização, ou o de coadjuvante nas práticas disciplinares da sociedade de controle, que faz com que os indivíduos passem a se sentir cada vez mais responsáveis por seu adoecimento e, conseqüentemente, pela manutenção de sua saúde.

\section{Nota}

1 Segundo Canguilhem (1990, p. 27), Comte atribuía a Broussais o mérito, que na realidade cabe a Bichat, e antes dele a Pinel, de ter proclamado que "todas as doenças aceitas como tal, são apenas sintomas, e que não poderiam existir perturbações das funções vitais sem lesões dos órgãos, ou melhor, de tecidos".

\section{REFERÊNCIAS}

CANGUILHEM, G. O normal e o patológico. Rio de Janeiro: Forense Universitária, 1990.

DEJOURS, C. Por um novo conceito de saúde. Revista Brasileira de Saúde Ocupacional, São Paulo, v. 54, n. 14, p. 7-11, 1986.

DELEUZE, G. Foucault. São Paulo: Brasiliense, 1991.

HARDT, M.; NEGRI, T. Império. Rio de Janeiro: Record, 2002.

FOUCAULT, M. Microfísica do poder. Rio de Janeiro: Graal, 1979. 
. O nascimento da clínica. Rio de Janeiro: Forense Universitária, 2003.

SARRIERA, J. C. et al. Paradigmas em psicologia: compreensões acerca da saúde e dos estudos. Epidemiológicos. Psicologia \& Sociedade, Porto Alegre, v. 2, n. 15, p. 88-100, 2003.

Recebido em outrubro/2003 Aceito em janeiro/2005 